\title{
Abundance of mycophagous arthropods present on different species of fungi in relation to resource abundance at different spatial scales
}

\author{
KazUO H. TAKAHASHI ${ }^{1 *}$, NoBUKo TUNO ${ }^{2}$ and TAKASHI KAGAYA ${ }^{1}$ \\ ${ }^{1}$ Laboratory of Forest Zoology, Department of Forest Science, Graduate School of Agricultural and Life Sciences, \\ The University of Tokyo, 1-1-1, Yayoi, Bunkyo-ku, Tokyo, 113-8657, Japan \\ ${ }^{2}$ Department of Vector Ecology and Environment, Institute of Tropical Medicine, Nagasaki University, Nagasaki, 852-8523, Japan
}

Key words. Host selection, fungi, fungus-visiting arthropods, spatial scale

\begin{abstract}
The abundance of Coleoptera, Diptera and Collembola on different species of fungi was investigated in relation to the size and abundance of fungal resources at different spatial scales; i.e., the size of the fungal fruiting body, the quality of resource in terms of number of conspecific sporophores growing within a radius of $50 \mathrm{~cm}$, crowding of the clumps of fruiting bodies, and the quality of resource within a plot $(20 \mathrm{~m} \times 30 \mathrm{~m})$. Multiple linear regression analyses showed that the influential spatial scale varied among the arthropod orders. The amount of resource at the scale of a clump made a significant contribution to the abundance of Coleoptera, and the fruiting body size significantly affected the abundance of Diptera on each fungal species. Collembolan abundance was significantly affected by the crowding of the clumps of fruiting bodies and the number of fruiting bodies per plot. These results suggest that the spatial distribution of fungal fruiting bodies may determine whether they are selected by arthropods visited.
\end{abstract}

\section{INTRODUCTION}

It is reported that the composition and abundance of mycophagous arthropod species differs on different species of fungi (Kimura et al., 1977; Wheeler \& Blackwell, 1984; Toda et al., 1999). This is largely due to differences in the chemical qualities of the host species, but the size of fruit bodies may also affect arthropod abundance. In fact, a number of studies (Worthen et al., 1996, 1998) record a positive correlation between the number of mycophagous insects and the size of the fruiting body of the host. Yamashita \& Hijii (2003) compared the abundance of mycophagous insects on different fungi and also observed that the number of mycophagous insects was affected by the size of the fungus.

Distribution pattern or aggregation of fungal resources at various spatial scales may influence the abundance of mycophagous insects on each species of fungus. The effect of resource distribution on organism abundance is often studied in the context of landscape ecology (Turner et al., 2001). It is suggested that patch quality (e.g., vegetation composition, patch size or resource abundance in patch) and characteristics of the surrounding landscape, including connectivity of the patches, affect the abundance of organisms in a patch (Delettre \& Morvan, 2000; Finn \& Giller, 2000; Turner et al., 2001; Bonte et al., 2003). A number of other examples suggesting the importance of landscape can be found in the literature (e.g., Lindenmayer \& Nix, 1993; Pearson, 1993; Pearson et al., 1995; Bolger et al,. 1997). However, it is rarely considered in studies on the abundance of mycophagous arthropods recorded on different species of fungi, although Worthen (1989) showed that the number of fungi-visiting mycophagous insects increases with host resource density.

The present study aims to evaluate how the abundance of fungal resources at different spatial scales affects how frequently they are visited by Coleoptera, Diptera and Collembola. We expect that these arthropods differ in their ecological characteristics and respond differently to the spatial heterogeneity in resource abundance.

\section{MATERIAL AND METHODS}

\section{Study site and methods}

Field surveys were conducted in four $20 \mathrm{~m} \times 30 \mathrm{~m}$ plots in forest at the foot of Mt Tsukuba $\left(36^{\circ} 13^{\prime} \mathrm{N}, 140^{\circ} 06^{\prime} \mathrm{W}\right)$ in central Japan. These plots were at altitudes between 150 and $370 \mathrm{~m}$ and were separated from each other by at least $500 \mathrm{~m}$. The forest was dominated by 38-44 year old pine trees (Pinus densiflora Sieb.). The average temperature in this area is $14.4^{\circ} \mathrm{C}$ and the annual precipitation was $1383 \mathrm{~mm}$ in 2000 (data from the Japanese Meteorological Agency).

Fruiting bodies of fungi may grow either solitarily or gregariously. In this study, "clumps" were defined as conspecific fruiting bodies growing within a radius of $50 \mathrm{~cm}$ of one another, because a group of fruiting bodies seldom exceeds this size. Locations of the clumps of fruiting bodies in the study plots and the number of fruiting bodies per clump were recorded.

All adult insects and other arthropods were collected from the clumps of fruiting bodies using an aspirator. Fifteen samples were collected between May and November 2000. The mean number of each arthropod taxon collected per fruiting body was determined for each fungal species by dividing the total number collected by the total number of fruiting bodies sampled. In this study, arthropods were collected from a total of 7374 fruiting bodies ( 585 clumps) belonging to 97 species of fungi (Appendix 1). Arthropod larvae found on the fruiting bodies were not

\footnotetext{
* Present address for correspondence: Ecology and Genetics, Graduate School of Environmental Earth Science, Hokkaido Univer-
} sity, Kita 10 Nishi 5, Sapporo 060-0810, Japan; e-mail: kazu@ees.hokudai.ac.jp 
included in this study since their distribution is largely determined by ovipositing females.

\section{Analysis}

Multiple linear regression and model selection

The analysis was made for the orders Coleoptera, Diptera and Collembola, although drosophilids were identified to species and other arthropods to family or order to provide more detailed information on biodiversity. It was difficult to determine whether fungal species on which no insects were observed should be considered as available for insects: they may be either unavailable, or available but not found. The latter is important for our analysis but not the former, and it is difficult to discriminate between them. To resolve this problem, analyses were conducted using two data sets: data set I contained only fungal species from which Coleoptera, Diptera or Collembola were collected, and data set II all fungal species. As a consequence, 62 fungal species were included in the former and 97 in the latter data set (Appendix 1). The following parameters representing characteristics of resource abundance at different spatial scales were determined for each fungal species: the size of the fruiting body, the average number of conspecific fruiting bodies per clump (density of fruiting bodies within a clump), crowding of the clumps of fruiting bodies, and the average number of clumps of all fungal species per plot (clump number). The size of the fruiting bodies was classified according to Imazeki \& Hongou (1987, 1989), Imazeki et al. (1988) and Hongou et al. (1994): 1 (small), 2 (medium) and 3 (large). The degree of crowding of the clumps of fruiting bodies of each species was evaluated by the average nearest neighbor distance (NND) from the focal clump of fruiting bodies to the nearest (conspecific or allospecific) clump of fruiting bodies within a plot. It is desirable to determine NND and clump number in situations where a single species is observed in a plot. However, this did not occur in this study.

To evaluate whether or not the abundance of arthropods (i.e., the mean number of arthropods per fruiting body) on each species of fungus was dependent on the parameters fruiting body size, fruiting body density within a clump, NND and clump number for each species of fungus, multiple linear regression analyses were performed for all possible linear combinations of these parameters (i.e., 15 combinations). The number of arthropods, density of fruiting bodies within a clump, NND and number of clumps were log transformed to normalize the distributions.

Although phylogenetically independent methods of data analysis (Felsenstein, 1985) were preferred, they could not be used because of the lack of phylogenetic information on the fungi.

Model selections

Three criteria - adjusted $r^{2}$, Akaike's Information Criterion (AIC; Akaike, 1978) and Schwarz Bayesian Information Criterion (BIC; Schwarz, 1978) - were calculated for all regression models. The most parsimonious model was selected:

$$
\text { Adjusted } r^{2}=1-\frac{S S_{\text {Residual }}[n-(p+1)]}{S S_{\text {Total }} /(n-1)}
$$

where $n$ is the number of observations, $p$ is the number of predictors included in the model, and $S S$ is the sum of squares. A larger value of adjusted $r^{2}$ indicates a better fit.

$$
\begin{aligned}
& A I C=n\left[\ln \left(S S_{\text {Residual }}\right)\right]+2(p+1)-n \ln (n), \\
& B I C=n\left[\ln \left(S S_{\text {Residual }}\right)\right]+(p+1) \ln (n)-n \ln (n) .
\end{aligned}
$$

For both AIC and BIC, smaller values indicate a better, more parsimonious model (Quinn \& Keough, 2002).

\section{Hierarchical partitioning}

The independent capacities of four predictor variables to explain the variations in insect abundance were determined by hierarchical partitioning (Chevan \& Sutherland, 1991). Hierarchical partitioning splits the total $r^{2}$ for each predictor (i.e., the $r^{2}$ for the linear relationship between the dependent variable and each predictor) into two additive components: the "independent" contribution $(I)$, which is a partitioning of the $r^{2}$ for the full model with all predictors; and the "joint" contribution $(J)$ along with other predictors. The independent contribution for each predictor is calculated by measuring the improvement in the fit of all models with a particular predictor compared to the equivalent model without that predictor, and averaging the improvement in fit across all possible models with that predictor. The joint contribution represents the variation in the dependent variable that is shared between two or more predictors. The joint contribution for each predictor is calculated from the difference between the squared partial correlation for the model relating the dependent variable to that predictor, and the average $r^{2}$, representing the already determined independent contribution of that predictor.

The significance of each independent contribution $I$ was tested using a randomization approach (MacNally, 2002). The data matrix was randomized 100 times and the distribution of $I \mathrm{~s}$ for each predictor was computed. If the observed value $I_{\mathrm{obs}}$ was extreme relative to the generated distribution (i.e., $I_{\text {obs }}$ was equal to or less than the fifth smallest generated $I$ ), then the predictor was taken as significant $(a=0.05)$.

\section{RESULTS}

\section{Fungi and insects}

Collybia confluens, Tylopilus castaneiceps, Mycena pura, Collybia peronata, Rhodophyllus rhodopolius, Trametes versicolor, Trichaptum abietinum and Xeromphalina campanella were the commonly observed fungi at our study site (Appendix 1). A total of 2824 invertebrates belonging to 60 taxa were collected from these fungi (Appendix 2). The dominant orders were Coleoptera (385 individuals), Diptera (379) and Collembola (1648). Of the Coleopteran families the Staphylinidae (68\%) and Erotylidae (12\%) were dominant, while drosophilids $(71 \%)$ dominated the Diptera and the Hypogasturidae $(83 \%)$ the Collembola.

\section{Best regression model}

All the selection criteria in both data sets (I and II) selected the same model with one predictor of coleopteran abundance, density of fruiting bodies within a clump (Table 1). For both data sets this predictor made a positive and significant $(P<0.05)$ contribution.

For Diptera, adjusted $r^{2}$ and AIC with data set I selected a model with three predictors, fruiting body size, density of fruiting bodies within a clump and NND. Fruiting body size and density of fruit body within a clump made a positive and significant $(P<0.05)$ contribution, whereas NND a negative and marginally non-significant contribution $(P=0.063)$. BIC with data set I selected a model with one predictor, fruiting body size, which made a positive and significant contribution. In analyses of data set II, adjusted $r^{2}$ and AIC selected a model with two predictors, fruiting body size and density of fruiting bodies within a clump, while BIC again selected a model with one predic- 
TABLE 1. Multiple linear regression models selected for Coleoptera, Diptera and Collembola recorded on different species of fungi; dataset I without species of fungi from which no Coleoptera, Diptera or Collembola insect were collected and dataset II included all the species of fungi. Only one model was selected for Collembola and Coleoptera,whereas two models were selected for Diptera using dataset I. Only one model was selected for Coleoptera, whereas two models were selected for Diptera and Collembola using dataset II. See text for details of model selection.

\begin{tabular}{|c|c|c|c|c|c|}
\hline & Coefficient & $\mathrm{SE}$ & $t$ & $p$ & Tolerance \\
\hline \multicolumn{6}{|l|}{ Dataset I } \\
\hline \multicolumn{6}{|l|}{ Coleoptera } \\
\hline $\log _{10}$ density of fruiting bodies within a clump & 0.199 & 0.060 & 3.304 & 0.002 & 1.000 \\
\hline Constant & 0.332 & 0.060 & 5.540 & $<0.001$ & \\
\hline \multicolumn{6}{|l|}{ Diptera } \\
\hline fruiting body size & 0.306 & 0.067 & 4.547 & $<0.001$ & 0.815 \\
\hline $\log _{10}$ density of fruiting bodies within a clump & 0.155 & 0.068 & 2.273 & 0.027 & 0.792 \\
\hline $\log _{10}$ NND & -0.123 & 0.065 & -1.895 & 0.063 & 0.877 \\
\hline Constant & 0.411 & 0.060 & 6.806 & $<0.001$ & \\
\hline \multirow[t]{2}{*}{$\mathrm{b}$} & 0.232 & 0.063 & 3.673 & $<0.001$ & 1.000 \\
\hline & 0.411 & 0.063 & 6.554 & $<0.001$ & \\
\hline \multicolumn{6}{|l|}{ Collembola } \\
\hline $\log _{10}$ no. of clump & 0.242 & 0.100 & 2.414 & 0.019 & 0.676 \\
\hline $\log _{10}$ NND & 0.212 & 0.100 & 2.111 & 0.039 & 0.676 \\
\hline Constant & 0.754 & 0.082 & 9.226 & $<0.001$ & \\
\hline \multicolumn{6}{|l|}{ Dataset II } \\
\hline \multicolumn{6}{|l|}{ Coleoptera } \\
\hline \multirow{2}{*}{$\begin{array}{r}\log _{10} \text { density of fruiting bodies within a clump } \\
\text { Constant }\end{array}$} & 0.155 & 0.041 & 3.776 & $<0.001$ & 1.000 \\
\hline & 0.201 & 0.041 & 4.944 & $<0.001$ & \\
\hline \multicolumn{6}{|l|}{ Diptera } \\
\hline fruiting body size & 0.190 & 0.047 & 4.058 & $<0.001$ & 0.927 \\
\hline $\log _{10}$ density of fruiting bodies within a clump & 0.090 & 0.047 & 1.935 & 0.056 & 0.927 \\
\hline Constant & 0.256 & 0.045 & 5.726 & $<0.001$ & \\
\hline \multirow[t]{2}{*}{$\mathrm{b}$} & 0.165 & 0.046 & 3.621 & $<0.001$ & 1.000 \\
\hline & 0.256 & 0.045 & 5.645 & $<0.001$ & \\
\hline \multicolumn{6}{|l|}{ Collembola } \\
\hline \multirow[t]{4}{*}{$\mathrm{a}$} & 0.182 & 0.071 & 2.554 & 0.012 & 0.772 \\
\hline & 0.138 & 0.071 & 1.929 & 0.057 & 0.769 \\
\hline & 0.096 & 0.063 & 1.522 & 0.131 & 0.992 \\
\hline & 0.466 & 0.062 & 7.470 & $<0.001$ & \\
\hline \multirow{2}{*}{$\begin{array}{l}\text { no. of clump } \\
\text { Constant }\end{array}$} & 0.119 & 0.064 & 2.111 & 0.039 & 1.000 \\
\hline & 0.466 & 0.064 & 7.296 & $<0.001$ & \\
\hline
\end{tabular}

tor, fruiting body size. In both models, only fruiting body size made a positive and significant contribution.

For Collembola, all the selection criteria selected the same model in data set I with two predictors, number of clumps and NND. Both predictors made positive and significant $(P<0.05)$ contributions. In the analysis with data set II, adjusted $r^{2}$ and AIC selected a model with three predictors, number of clumps, density of fruiting bodies within a clump and fruiting body size, while BIC selected a model with one predictor, number of clumps in a plot. In both models, only number of clumps had positive and significant $(P<0.05)$ contribution. The low $\left(r^{2}=\right.$ $0.001-0.324)$ correlations between the predictors and high values of tolerance for each predictor (Table 1) suggested that multicollinearity was not a problem in this case.

\section{Hierarchical partitioning}

Density of fruiting bodies within a clump made the largest independent contribution to the hierarchical partitioning of $r^{2}$ for Coleoptera, for both data sets (Fig. 1).
According to the randomization test, only the density of fruiting bodies within a clump had a significant independent effect for both data sets. For Diptera, fruiting body size made the largest independent contribution (Fig. 1), and the randomization test showed that the effect of fruiting body size was significant for both data sets. For Collembola, number of clumps showed the largest independent contribution and NND showed the second largest contribution for both data sets (Fig. 1). The randomization test demonstrated that only the effect of number of clumps was significant for both data sets.

\section{DISCUSSION}

Results of multiple linear regression analyses appeared to be only slightly affected by the inclusion or exclusion of fungi not visited by insects.

The significant parameters in multiple linear regressions predicting the abundance of arthropods on each species of fungus varying greatly among the arthropod orders: the density of fruiting bodies within a clump in Coleoptera, the fruiting body size in Diptera, and the 


\section{(a) Coleoptera}

\section{Dataset I}

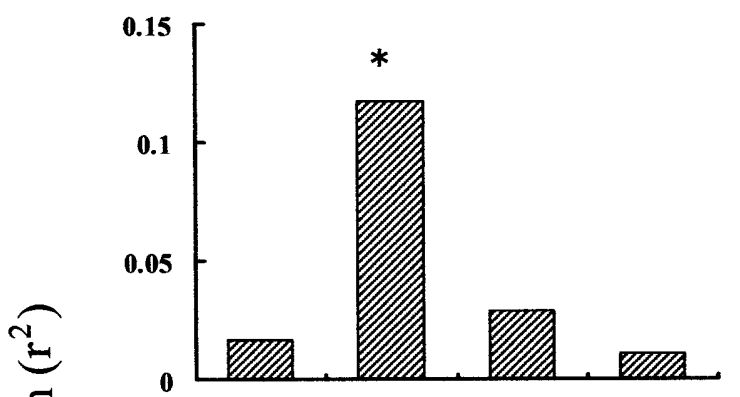

(b) Diptera

Dataset I

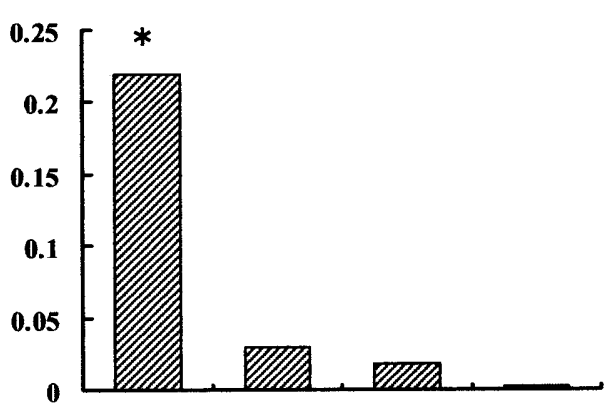

(c) Collembola

Dataset I

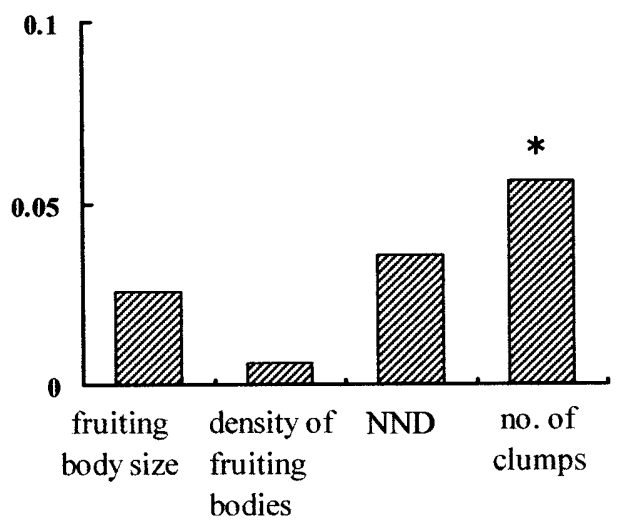

\section{Dataset II}

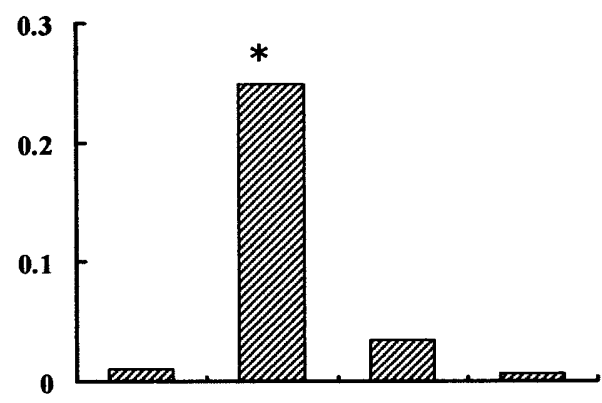

Dataset II

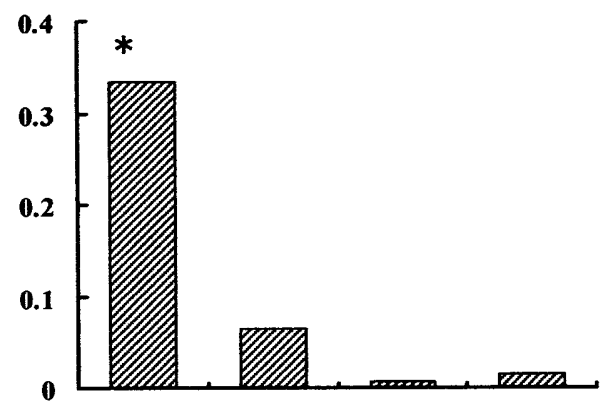

Dataset II

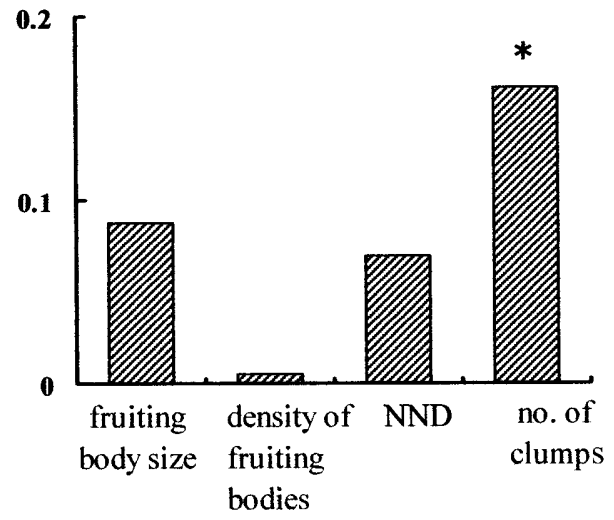

Fig. 1. Independent contribution of four predictor variables (fruiting body size, density of fruiting bodies within a clump, NND, number of clumps) to the hierarchical partitioning of $r^{2}$ for multiple regression analyses of arthropod abundance recorded on different species of fungi; (a) Coleoptera, (b) Diptera and (c) Collembola; for data sets I and II (excluding or including (respectively) species of fungi from which no Coleoptera, Diptera and Collembola were collected). ${ }^{*}$ : significant $(P<0.05)$ deviation from 0 was suggested by the randomization test.

crowding of the clumps of fruiting bodies and the number of clumps (i.e., the number of clumps of fruiting bodies per plot) in Collembola. Thus, arthropods of different orders respond to resource abundance at different spatial scales.

The density of fruiting bodies within a clump had a significant positive effect on the abundance of Coleoptera on each species of fungus, whereas the fruiting body size did not. Thus, Coleoptera selected fungi with a larger number of fruiting bodies within a clump. This may be related to the characteristics of their larvae. Larvae of the dominant coleopteran taxa, Staphylinidae and Erotylidae, have legs and are able to move between fruiting bodies within a clump, and therefore selection of dense clumps would ensure that the larvae have access to a larger quantity of food.

On the other hand, fruiting body size showed a significant positive contribution to the abundance of Diptera in models selected by all criteria and also by hierarchical partitioning, indicating that they select fungi with larger fruiting bodies. Worthen (1989) also determined the number of flies emerging from fruiting bodies in patches of different fruiting body density. He found no differences in the mean number of drosophilid flies emerging 
from single fruiting bodies in high vs. low density patches. This also suggests that resource density within a patch did not affect the abundance of flies per resource unit. The selection of fungi by Diptera may also be related to the larval characteristics as in Coleoptera. Dipterous larvae do not have limbs and are unlikely to move between fruiting bodies even within a clump. Therefore, Diptera may select fungi with large fruiting bodies, rather than large clumps in order to provide their larvae with a large amount of food. Worthen (1989) studied the dispersal of adults of mycophagous Drosophila, the dominant Diptera in this study, and observed that most individuals stayed within $20 \mathrm{~m}$ of the release point. A few were recaptured at $28 \mathrm{~m}$ or $>60 \mathrm{~m}$ distant sites. Similar results are presented by Montague (1985). Adult Diptera move freely and search out high-quality (i.e., larger) fruiting bodies at smaller than the within-plot scale (20-30 m), although they rarely move between plots. There are a number of reports of long distance migrations by Diptera (Coyne et al., 1982; Coyne \& Milstead, 1987; Kimura, 1992; Kimura \& Beppu, 1993) but the frequency of long distance migration and its importance in habitat selection at larger spatial scales are unknown.

NND (distance to the nearest clump of fruiting bodies) and number of clumps (number of clumps of fruiting bodies per plot) made significant positive contributions to collembolan abundance on each species of fungus. The positive contribution of NND indicates that the abundance of Collembola increases with decreasing crowding of the clumps of fruiting bodies. This may suggest that if clumps of fruiting bodies are very closely located, a collembolan assembly splits into small subassemblies. There are two possible interpretations of the positive contribution of the number of clumps: 1) Collembola move to plots rich in clumps of fruiting bodies from surrounding areas; or 2) Collembola reproduce quickly, thereby increasing in numbers in plots rich in clumps of fruiting bodies. For the first interpretation to hold Collembola need to be highly mobile if they are to locate plots rich in the fruiting bodies. However, if they are highly mobile the contribution of the density of fruiting bodies within a clump and fruiting body size should be positive, as observed in Coleoptera and Diptera. For the second interpretation to hold, the rate of population increase of Collembola should be high enough to enable them to track the increase in the number of clumps. Takeda (2002) reports that most Collembola require one to several months to reach maturity, and are unlikely to reproduce during periods as short as that between emergence and death of a fungal fruiting body. It is possible that the abundance of Collembola was determined by unknown factors (e.g., the amount of underground mycelia), which are correlated with the number of clumps of fruiting bodies.

The chemical properties of fruiting bodies were not investigated but are likely to have a pronounced effect on the abundance of arthropods. In addition, the present analyses were made at the level of arthropod order. An analysis at a lower taxonomic level could give a more detailed picture. Our study does, however, illustrate the importance of the spatial distribution of fungal resources on the abundances of arthropods that visit them. Welldesigned experiments are needed to clarify the combined effects of chemical properties and spatial distribution patterns of fungi on the abundance of arthropods.

ACKNOWLEDGEMENTS. We thank M.T. Kimura for his valuable contributions to the manuscript and S. Ugawa for help in the field.

\section{REFERENCES}

AKaIKe H. 1978: A Bayesian analysis of the minimum AIC procedure. Ann. Inst. Statist. Math. 30: 9-14.

Bolger D.T., Scott T.A. \& Rotenberry J.T. 1997: Breeding bird abundance in an urbanizing landscape in coastal southern California. Conserv. Biol. 11: 406-421.

Bonte D., Lens L., Maelfait J.P., Hoffmann M. \& KuiJken E. 2003: Patch quality and connectivity influence spatial dynamics in a dune wolfspider. Oecologia 135: 227-233.

Chevan A. \& Sutherland M. 1991: Hierarchical partitioning. Am. Stat. 45: 90-96.

Coyne J.A. \& MilsteAd B. 1987: Long-distance migration of Drosophila. 3. Dispersal of D. melanogaster alleles from a Maryland orchard. Am. Nat. 130: 70-82.

Coyne J.A., Boussy I.A., Prout T., Bryant S.H., Jones J.S. \& Moore J.A. 1982: Long-distance migration of Drosophila. Am. Nat. 119: 589-595.

Delettre Y.R. \& Morvan N. 2000: Dispersal of adult aquatic Chironomidae (Diptera) in agricultural landscapes. Freshwater Biol. 44: 399-411.

Felsenstein J. 1985: Phylogenies and the comparative method. Am. Nat. 125: 1-15.

FinN J.A. \& Giller P.S. 2000: Patch size and colonisation patterns: an experimental analysis using north temperate coprophagous dung beetles. Ecography 23: 315-327.

Hongou T., Ueda T. \& Izawa M. 1994: Mushrooms. Yama-Kei Field Books 10. Yama-Kei Publishers, Tokyo.

IMAZEKi R. \& Hongou T. 1987: Colored Illustrations of Mushrooms of Japan Vol. 1. Hoikusha, Osaka, 325 pp. [in Japanese].

IMAZEKi R. \& Hongou T. 1989: Colored Illustrations of Mushrooms of Japan Vol. 2. Hoikusha, Osaka, 239 pp. [in Japanese].

ImAZeKi R., Otani Y. \& Hongou T. 1988: Fungi of Japan. YAMA-KEI Publishers, Tokyo, 642 pp. [in Japanese].

KimURA M.T. 1992: Tethered-flight activity of drosophilids (Diptera: Drosophilidae) in relation to habitat and resource distribution. J. Insect Behav. 5: 395-401.

KimURA M.T. \& BepPu K. 1993: Climatic adaptations in the Drosophila immigrans species group: seasonal migration and thermal tolerance. Ecol. Entomol. 18: 141-149.

Kimura M.T., Toda M.J., Beppu K. \& Watabe H. 1977: Breeding sites of drosophilid flies in and near Sapporo, northern Japan, with supplementary notes on adult feeding habits. Kontyu 45: 571-582.

LindenMayer D.B. \& Nix H.A. 1993: Ecological principles for the design of wildlife corridors. Conserv. Biol. 7: 627-630.

MAC NALLY R. 2002: Multiple regression and inference in ecology and conservation biology: further comments on identifying important predictor variables. Biodivers. Conserv. 11: 1397-1401.

Montague J.R. 1985: Body size, reproductive biology, and dispersal behaviour among artificial baits in D. falleni. Drosoph. Inf. Serv. 61: 123-126. 
Pearson S.M. 1993: The spatial extent and relative influence of landscape-level factors on wintering bird populations. Landscape Ecol. 8: 3-18.

Pearson S.M., Turner M.G., Wallace L.L. \& Romme W.H. 1995: Winter habitat use by large ungulates following fires in northern Yellowstone National Park. Ecol. Appl. 5: 744-755.

Quinn G.P. \& Keough M.J. 2002: Experimental Design and Data Analysis for Biologists. Cambridge University Press, Cambridge, $556 \mathrm{pp}$.

Schwarz G. 1978: Estimating the dimension of a model. Ann. Stat. 6: 461-464

TAKEDA H. 2002: Forest Inhabited by Collembolans. Kyoto University Press, Kyoto (tentative translation).

Toda M.J., Kimura M.T. \& Tuno N. 1999: Coexistence mechanisms of mycophagous drosophilids on multispecies fungal hosts: aggregation and resource partitioning. J. Anim. Ecol. 68: 794-803.
Turner M.G., Gardner R.H. \& O'Neill R.V. 2001: Landscape Ecology in Theory and Practice. Springer-Verlag, New York, $404 \mathrm{pp}$.

Wheeler Q. \& Blackwell M. 1984: Fungus-Insect Relationships. Columbia University Press, New York, 514 pp.

Worthen W.B. 1989: Effects of resource density on mycophagous fly dispersal and community structure. Oikos 54: 145-153.

Worthen W.B., Carswell M.L. \& Kelly K.A. 1996: Nested subset structure of larval mycophagous fly assemblages: nestedness in a non-island system. Oecologia 107: 257-264.

Worthen W.B., Jones M.T. \& Jetton R.M. 1998: Community structure and environmental stress: desiccation promotes nestedness in mycophagous fly communities. Oikos 81: 45-54.

Yamashita S. \& HiJI N. 2003: Effects of mushroom size on the structure of a mycophagous arthropod community: comparison between infracommunities with different types of resource utilization. Ecol. Res. 18: 131-144.

Received March 26, 2004; revised September 22, 2004; accepted October 18, 2004

APPENDIX 1. The species of fungus, number of clumps and number of fruiting bodies.

\begin{tabular}{|c|c|c|c|}
\hline Family & Species & No. of clumps & No. of fruiting bodies \\
\hline Geoglossaceae & Microglossum rufum (Schwein.) & 1 & 1 \\
\hline Sarcosomataceae & Plectania nannfeldtii Korf & 1 & 1 \\
\hline Helvellaceae & Helvella macropus (Pers.: Fr.) Karst. & 1 & 1 \\
\hline Auriculariaceae & Auricularia polytricha (Mont.) Sacc. & 2 & 19 \\
\hline Coniophoraceae & Serpula lacrymans (Wulfen) J. Schröt. * & 1 & 76 \\
\hline \multirow[t]{2}{*}{ Thelephoraceae } & Thelephora aurantiotincta Corner * & 2 & 3 \\
\hline & Thelephora palmata Scop.: Fr. * & 14 & 14 \\
\hline \multirow[t]{11}{*}{ Polyporaceae } & Polyporus arcularius Batsch.: Fr. * & 1 & 1 \\
\hline & Polyporellus varius (Pers. : Fr.) Karst. & 2 & 5 \\
\hline & Polyporus tenuiculus (Beauv.) Fr. * & 1 & 2 \\
\hline & Cryptoporus volvatus (Peck) Shear. & 5 & 18 \\
\hline & Coriolus versicolor (L.: Fr.) Quél. * & 11 & 1568 \\
\hline & Trichaptum abietinum (Dicks.:Fr.) Ryv. * & 14 & 2308 \\
\hline & Fomitopsis pinicola (Fr.) Karst. & 2 & 1 \\
\hline & Polyporaceae sp1. * & 3 & 4 \\
\hline & Polyporaceae sp2.* & 1 & 1 \\
\hline & Polyporaceae sp3. & 1 & 2 \\
\hline & Polyporaceae sp4. & 1 & 211 \\
\hline Pleurotaceae & Schizophyllum commune Fr. : Fr. * & 1 & 1 \\
\hline \multirow[t]{19}{*}{ Tricholomataceae } & Laccaria bicolor Hongo * & 4 & 9 \\
\hline & Clitocybe fragrans (With.: Fr.) Kummer. & 2 & 4 \\
\hline & Armillariella tabescens (Scop.) Sing. * & 6 & 13 \\
\hline & Callistosporium luteoolivaceum (Berk. et Curt.)Sing.* & 16 & 335 \\
\hline & Collybia dryophila (Bull.: Fr.) Kummer * & 12 & 34 \\
\hline & Collybia butyracea (Bull.: Fr.) Quél. * & 11 & 41 \\
\hline & Collybia peronata (Bolt.: Fr.) Kummer * & 23 & 60 \\
\hline & Collybia confluens (Pers.: Fr.) Kummer * & 66 & 324 \\
\hline & Oudemansiella platyphylla (Pers.:Fr.) Moser in Gams.* & 4 & 6 \\
\hline & Oudemansiella radicata (Relhan : Fr.) Sing. * & 3 & 4 \\
\hline & Strobilurus stephanocystis (Hora) Sing. & 5 & 7 \\
\hline & Marasmius pulcherripes Peck. & 1 & 2 \\
\hline & Micromphale sp. * & 4 & 24 \\
\hline & Mycena pura (Pers. : Fr.) Kummer. * & 24 & 126 \\
\hline & Mycena vulgaris (Pers.: Fr.) Quél. & 5 & 17 \\
\hline & Xeromphalina campanella (Batsch:Fr.) Maire. * & 4 & 767 \\
\hline & Xeromphalina cauticinalis (Fr.) Kuhn.\& Maire. * & 16 & 393 \\
\hline & Cyptotrama asprata (Berk.) Redhead \& Ginns. & 1 & 1 \\
\hline & Tricholomataceae sp. $*$ & 19 & 215 \\
\hline
\end{tabular}




\begin{tabular}{|c|c|c|c|}
\hline Family & Species & No. of clumps & No. of fruiting bodies \\
\hline \multirow[t]{10}{*}{ Amanitaceae } & Amanita pseudogemmata Hongo * & 7 & 7 \\
\hline & Amanita sychnopyramis Ccorner et. Bas f. subannulata Hongo * & 4 & 12 \\
\hline & Amanita hemibapha (Berk. \& Br.) Sacc. * & 2 & 2 \\
\hline & Amanita virosa (Fr.) Bertillon * & 5 & 5 \\
\hline & Amanita volvata (Peck) Martin * & 1 & 4 \\
\hline & Amanita spissacea Imai & 2 & 4 \\
\hline & Amanita castanopsidis Hongo * & 4 & 5 \\
\hline & Amanita spreta (Peck) Sacc. * & 3 & 3 \\
\hline & Amanita pseudoporphyria Hongo * & 16 & 23 \\
\hline & Amanita sp. * & 4 & 6 \\
\hline \multirow[t]{11}{*}{ Agaricaceae } & Macrolepiota sp. & 1 & 1 \\
\hline & Leucoagaricus rubrotinctus (Peck) Sing. & 6 & \\
\hline & Leucocoprinus fragilissimus (Rav.)Pat* & 8 & 8 \\
\hline & Leucocoprinus subglobisporus Hongo & 2 & 3 \\
\hline & Leucocoprinus otsuensis Hongo * & 3 & 7 \\
\hline & Agaricus subrutilescens (Kauffm.) Hotsom et Stuntz. & 1 & \\
\hline & Agaricus abruptibulbus Peck. * & 1 & 1 \\
\hline & Agaricus praeclaresquamosus Freeman & 1 & 1 \\
\hline & Lepiota cristata (Weinm. : Fr.) Gill. S. Lat. & 4 & 9 \\
\hline & Lepiota cygnea J. Lange & 1 & 2 \\
\hline & Agaricaceae sp. * & 2 & 3 \\
\hline Coprinaceae & Psathyrella candolliana (Fr. : Fr.) Maire. * & 12 & 22 \\
\hline Bolbitiaceae & Agrocybe praecox (Pers.: Fr.) Fayod & 1 & 1 \\
\hline Strophariaceae & Naematoloma fasciculare (Hudson : Fr.) Karst. * & 2 & 51 \\
\hline \multirow[t]{7}{*}{ Cortinariaceae } & Inocybe fastigiata (Shaeff.) Quél. * & 1 & 1 \\
\hline & Inocybe cookei Bres. * & 1 & 1 \\
\hline & Inocybe asterospora Quél. * & 1 & 2 \\
\hline & Inocybe kobayasii Hongo * & 2 & 3 \\
\hline & Inocybe sp. * & 2 & 3 \\
\hline & Cortinarius pseudopurpurascens Hongo & 2 & 2 \\
\hline & Dermocybe cinnamomea (L.:Fr.) Wünsche & 2 & 2 \\
\hline \multirow[t]{6}{*}{ Rhodophyllaceae } & Rhodophyllus nidorosus (Fr.) Quél. * & 2 & 6 \\
\hline & Rhodophyllus rhodopolius (Fr.) Kummer.* & 23 & 44 \\
\hline & Rhodophyllus murraii (Berk. et Curt.) Sing. & 2 & 6 \\
\hline & Rhodophyllus sinuatus (Bull.: Fr.) Sing. & 1 & 1 \\
\hline & Rhodophyllus crassipes (Imaz. et Toki) Imaz. et Hongo * & 1 & 1 \\
\hline & Rhodophyllaceae sp. & 1 & 1 \\
\hline Paxillaceae & Paxillus curtisii Berk. In Berk et Curt. & 1 & 2 \\
\hline \multirow[t]{11}{*}{ Boletaceae } & Gyroporus cyanescens (Bull.: Fr.) Quél.* & 1 & 1 \\
\hline & Suillus granulatus (L. : Fr.) O. Kuntze * & 4 & 8 \\
\hline & Xerocomus chrysenteron (Bull.) Quél. & 2 & 3 \\
\hline & Xerocomus nigromaculatus Hongo * & 4 & 11 \\
\hline & Boletus edulis Bull.:Fr. & 1 & 1 \\
\hline & Boletus calopus Pers.:Fr. * & 11 & 25 \\
\hline & Boletus chrysenteroides (Snell) Snell & 1 & 1 \\
\hline & Tylopilus neofelleus Hongo * & 11 & 20 \\
\hline & Tylopilus castaneiceps Hongo * & 36 & 60 \\
\hline & Leccinum hortonii (AH Smith et Thiers) Hongo et Nagasawa & 3 & 3 \\
\hline & Boletacea sp. * & 13 & 16 \\
\hline \multirow[t]{7}{*}{ Russulaceae } & Russula japonica Hongo * & 6 & 5 \\
\hline & Russula cyanoxantha (Schaeff.) Fr. & 1 & 1 \\
\hline & Russura emetica (Schaeff.: Fr.) S. F. Gray * & 5 & 5 \\
\hline & Lactarius hygrophoroides Berk. Et Curt. & 7 & 6 \\
\hline & Lactarius gracilis Fr. * & 6 & 12 \\
\hline & Lactarius ochrogalactus & 1 & 1 \\
\hline & Russulaceae sp. * & 11 & 11 \\
\hline Geastraceae & Geastrum mirabile (Mont.) Fisch. & 3 & 5 \\
\hline \multirow[t]{2}{*}{ Lycoperdaceae } & Lycoperdon perlatum Pers.:Pers. * & 3 & 3 \\
\hline & Lycoperdon spadiceum Pers. * & 2 & 2 \\
\hline Unknown & Unknown * & 27 & 287 \\
\hline Total & & 585 & 7374 \\
\hline
\end{tabular}

*Fungal species on which arthropods were collected 


\begin{tabular}{l}
\hline APPENDIX 2. Taxa and individual numbers of adult \\
and other arthropods. \\
\hline Order, suborder, family or species \\
\hline Opiliones \\
Phalangium \\
Acari \\
Gamasida \\
Prostigmata \\
Oribatida \\
Gdellidae \\
Galumna \\
Araneae \\
Theridiosomatidae \\
Linyphiidae \\
Araneidae \\
Ctenidae \\
Gnaphosidae \\
Sparassidae \\
Thomisidae \\
Philodromidae \\
Salticidae \\
Isopoda \\
Lithobiomorpha \\
Collembola \\
Hypogasturidae \\
Neanuridae \\
Tomoceridae \\
Oncopoduridae \\
Entomobryidae \\
Sminthuridinae \\
Thysanura \\
Machilidae \\
Orthoptera \\
Gryllidae \\
Psocoptera \\
Psocoptera \\
Hemiptera \\
Heteroptera \\
Lepidoptera \\
\end{tabular}

Coleoptera

Leiodidae 2

Catopidae 23

Staphylinidae 263

Scarabaeidae 6

Throscidae 1

Nitidulidae 4

Erotylidae $\quad 62$

Endomychidae 1

Ciidae 22

Tenebrionidae 1

Coleoptera larvae $\quad 125$

Hymenoptera

except for Formicidae 33

Formicidae

Myrmicinae 126

Formicinae $\quad 91$

Ponerinae 15

Diptera

Mycetophilidae 5

Sciaridae 24

Cecidomyiidae $\quad 16$

Psychodidae 3

Phoridae 51

Syrphidae 1

Sphaeroceridae 9

Drosophilidae

Mycodrosophila. gratiosa (de Meijere) 15

M. koreana Lee \& Takada

M. poecilogastra (Loew) 2

Scaptomyza sp.

Drosophila angularis Okada $\quad 87$

D. brachynephros Okada 12

D. bizonata Kikkawa \& Peng 145

D. sternopleuralis Okada \& Kurokawa 3

Chloropidae 2

Diptera larvae 383

Stylommatophora

Stylommatophora spp. 3

Philomycidae $\quad 9$

Total 3332 